\title{
Effects of Demographic Factors on Survival Time after a Diagnosis of Amyotrophic Lateral Sclerosis
}

\author{
Heather Jordan ${ }^{a}$ b Jerald Fagliano ${ }^{a}$ Lindsay Rechtman ${ }^{a, b}$ Daniel Lefkowitz ${ }^{a}$ \\ Wendy Kaye ${ }^{b}$ \\ aEnvironmental and Occupational Health Surveillance Program, New Jersey Department of Health, Trenton, N.J., and \\ ${ }^{b}$ McKing Consulting Corporation, Atlanta, Ga., USA
}

\section{Key Words}

Amyotrophic lateral sclerosis - Death certificates · Mortality · Survival curves $\cdot$ Hazard ratio

\begin{abstract}
Background: The Agency for Toxic Substances and Disease Registry established surveillance projects to determine the incidence, prevalence, and demographic characteristics of persons with Amyotrophic Lateral Sclerosis (ALS) in defined geographic areas. There is a need to characterize and account for the survival and prognostic factors among a population-based cohort of ALS cases in the United States. Methods: A cohort of incident cases diagnosed from 2009-2011 in New Jersey was followed until death or December 31, 2013, whichever happened first. Survival was assessed using Kaplan-Meier curves and Cox proportional hazards regression was used to identify prognostic factors. Results: Sixtyfour percent of incident cases died between 2009 and 2013, $93.7 \%$ specifically from ALS. Among the 456 cases studied in the survival analysis, the median survival from diagnosis was 21 months; $46 \%$ of cases survived longer than two years from diagnosis. Older age predicted shorter survival. While
\end{abstract}

(c) 2015 S. Karger AG, Basel

0251-5350/15/0442-0114\$39.50/0 there is some indication of differences because of sex, race, and ethnicity, these differences were not statistically significant when accounting for age. Conclusions: New Jersey mortality data were queried to determine the vital status of a cohort of incident ALS cases and used to investigate relationships between demographic factors and survival. Results are consistent with other population-based studies. Older age was a strong predictor of shorter survival time. Additional follow-up time is needed to characterize longerterm survival.

(c) 2015 S. Karger AG, Base

\section{Introduction}

Amyotrophic lateral sclerosis (ALS) is a rare disease that is characterized by progressive degeneration of both the upper and lower motor neurons. The median crude incidence rate among studies conducted around the world was 2.1 per 100,000 person-years (range: $0.3-3.6$ ), and the crude prevalence was 5.4 per 100,000 persons (range: 1.0-11.3) [1]. In New Jersey (N.J., USA), the ageadjusted incidence was 1.67 per 100,000 person-years

\section{KARGER 125}

E-Mail karger@karger.com www.karger.com/ned
Heather M. Jordan, MPH, CPH, MCHES

Environmental and Occupational Health Surveillance Program New Jersey Department of Health, P.O. Box 369

135 East State Street, 4th Floor, Trenton, NJ 08625 (USA)

E-Mail heather.jordan@doh.state.nj.us 
(2009-2011), and the point prevalence as of December 31,2011 , was 4.40 per 100,000 persons [2]. A higher incidence is associated with being older, male, white, and non-Hispanic [1-5].

Estimates of the median survival time from diagnosis range between 18 and 29 months [2, 6-9] and most ALS patients die within two to five years of diagnosis [10]. Older age is associated with shorter survival [7-9, 11-13], and there are conflicting reports of sex being a prognostic indicator $[6,8,9,11]$. Few studies have examined race as a prognostic factor $[7,8]$. There are limited survival data for persons with ALS in the United States. This report describes the survival time from the time of diagnosis among cases of ALS reported by neurologists in a defined geographic area (N.J., USA). The El Escorial criteria [14] were used to determine case eligibility.

\section{Materials and Methods}

A detailed description of the case ascertainment methodology is presented elsewhere [2]. Cases were reported by neurologists for all ALS patients who were N.J., USA residents, under the physician's care at some point between January 1, 2009 and December 31, 2011, and who met the El Escorial criteria [14]. There were 764 prevalent cases in this period, of which 493 cases were incident with the disease. Eighty-four percent of cases were 50 years of age or older at diagnosis, $55.1 \%$ were male, $83.2 \%$ were white, and $89.9 \%$ were non-Hispanic [2].

\section{Determination of Survival of Incident Cases}

Vital status, as of December 31, 2013, of the 493 incident cases was determined through a query of N.J. death records. Death certificates are retained within the N.J., USA Department of Health, where a certified nosologist reviews all electronic or hand-written information on the death certificate to ensure conformity with the International Classification of Disease revision 10 (ICD-10) $[15,16]$. Cases were matched to death records on a combination of variables: last name, first name, date of birth, last five digits of the social security number, sex, and address.

\section{Cause of Death}

Decedents were classified based on the causes assigned for death in their death certificates - that is, whether ALS was a cause for death - by a review of all contributing and underlying causes of death. A search of keywords was conducted and deaths were classified as due to ALS if any of the following keywords or variants appeared in any of the five causes of death: 'amyotrophic lateral sclerosis', 'ALS', 'amyotrophic', or 'Gehrig'.

\section{Analysis of Survival Time}

Survival time of a patient was calculated from the month and year of diagnosis to the month and year of death, regardless of the cause of death. Race was identified on the case reporting form as 'White', 'Black', 'Asian', 'Other', or 'Unknown'. Cases were excluded from analyses if race was 'Other' or 'Unknown', or if
Hispanic ethnicity was 'Unknown'. Age at diagnosis was categorized into four groups approximating quartiles of the distribution: less than 55 years; 55 to $<65$ years; 65 to $<75$ years; and 75 years or more.

Kaplan-Meier product-limit survival curves and median survival time were developed using the LIFETEST procedure in SAS $^{\circledR}$ version $9.2[17,18]$. Confidence limits on median survival times were based on the log-log transformation of the survivor function. Homogeneity in median survival time across strata of demographic groups was assessed using the log-rank test. Differences across strata are considered statistically significant for $p$ values less than 0.05 . The percent of ALS cases surviving beyond $6,12,18$, and 24 months past diagnosis was also determined for all cases and based on demographic strata. Confidence limits on survival percentages were derived using the normal approximation method or Wilson score method [17]. The multivariate Cox proportional hazard model was used to examine the effects of demographic factors on survival time, using the PHREG procedure in $\mathrm{SAS}^{\circledR}$ [17].

The project protocol was approved by the Centers for Disease Control and Prevention Institutional Review Board (IRB) and determined to be public health practice not requiring review by the N.J. Department of Health IRB.

\section{Results}

As of December 31, 2013, 64.1\% of incident cases (316/493) were known to be deceased. This proportion was higher among those diagnosed in 2009 (68.4\%) compared with those diagnosed in $2010(65.5 \%)$ and 2011 (58.5\%). For 93.7\% (296/316) of those known to be deceased, ALS was specified as the cause of death on the death certificate. Respiratory failure, aspiration, pneumonia, other neuromuscular disorders, sepsis, acute cardiac events, malnutrition, and chronic obstructive pulmonary disorder were among the causes of death listed for the 20 cases that did not list ALS as one of the causes of death.

In the remaining analyses, we excluded 37 cases on the basis of race being 'Other' or 'Unknown' or Hispanic ethnicity being 'Unknown'. Among the remaining 456 incident cases diagnosed during 2009-2011, the median survival time from the time of diagnosis to the time of death was 21 months (95\% CI 19, 25 months) (table 1). The median survival time varied significantly by age group from a high of 38 months (95\% CI 28, 45 months) for the age group $<55$ years, to a low of 11 months (95\% CI 9, 14 months) for those 75 years of age or older (table 1). The median survival time was shorter among females compared with that of males, among whites compared with that of blacks and Asians, and among non-Hispanics compared with that of Hispanics (table 1). Kaplan-Meier 
Fig. 1. Kaplan-Meier survival curves for incident NJ ALS cases with vital status determined through December 31, 2013, $\mathrm{n}=$ 456 , for all cases, by age group and by sex. (Of 493 incident cases, 37 cases were excluded whose race was 'unknown' or 'other', or whose Hispanic ethnicity was 'unknown'.) a All cases.

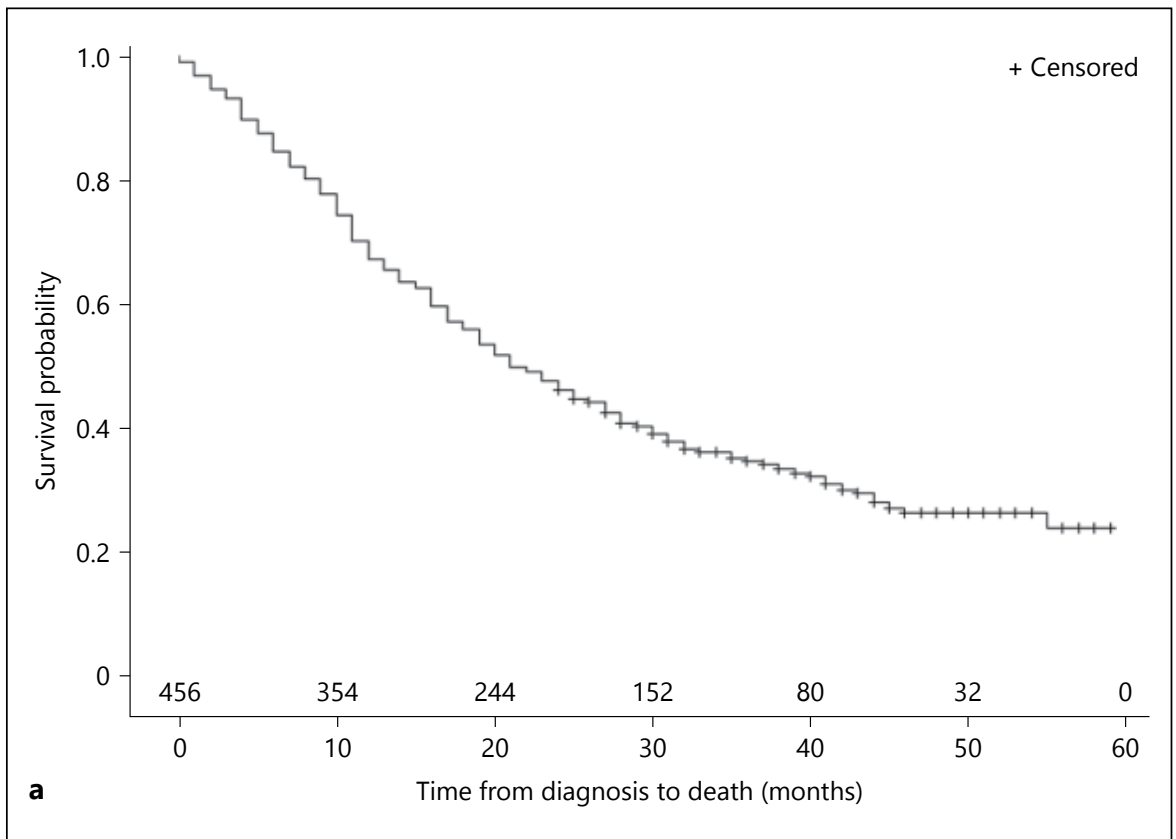

Table 1. Median survival times by demographic characteristic, $n=456^{*}$

\begin{tabular}{|c|c|c|c|}
\hline Parameter & $\begin{array}{l}\text { Number } \\
\text { of cases }\end{array}$ & $\begin{array}{l}\text { Median survival time } \\
(95 \% \text { CI }) \text { in months }\end{array}$ & $\begin{array}{l}\text { log-rank test of } \\
\text { equality over strata }\end{array}$ \\
\hline All cases & 456 & $21(19,25)$ & - \\
\hline \multicolumn{4}{|l|}{ Age group } \\
\hline$<55$ & 108 & $38(28,45)$ & \multirow{4}{*}{$\mathrm{p}<0.0001$} \\
\hline 55 to $<65$ & 131 & $30(22,41)$ & \\
\hline 65 to $<75$ & 115 & $17(12,23)$ & \\
\hline $75+$ & 102 & $11(9,14)$ & \\
\hline \multicolumn{4}{|l|}{ Sex } \\
\hline Male & 242 & $24(19,28)$ & \multirow[t]{2}{*}{$\mathrm{p}=0.050$} \\
\hline Female & 214 & $20(17,23)$ & \\
\hline \multicolumn{4}{|l|}{ Race } \\
\hline White & 405 & $20(18,24)$ & \multirow{3}{*}{$\mathrm{p}=0.031$} \\
\hline Black & 29 & $41(22,-)$ & \\
\hline Asian & 22 & $30(14,-)$ & \\
\hline \multicolumn{4}{|l|}{ Ethnicity } \\
\hline non-Hispanic & 431 & $21(19,24)$ & \multirow[t]{2}{*}{$\mathrm{p}=0.22$} \\
\hline Hispanic & 25 & $30(16,-)$ & \\
\hline
\end{tabular}

* Of 493 incident cases, 37 were excluded whose race was 'unknown' or 'other', or whose Hispanic ethnicity was 'unknown'.

- Upper confidence limit not estimated.

survival curves for all incident cases and for cases by age group and by sex are presented in figure 1 .

The percentages of ALS cases surviving beyond 6,12, 18 , and 24 months are shown in table 2 . For the 456 incident cases, $67 \%$ (95\% CI 63, 71) survived past 12 months and $46 \%(95 \%$ CI 41,51$)$ survived past 24 months. As age increases, the percentage of cases surviving beyond a certain time decreases; as many as $66 \%$ of those diagnosed with ALS before age 55 years survived 24 months, while only $23 \%$ of those diagnosed at age 75 years or older sur- 
Fig. 1. Kaplan-Meier survival curves for incident NJ ALS cases with vital status determined through December 31, 2013, $\mathrm{n}=$ 456 , for all cases, by age group and by sex. (Of 493 incident cases, 37 cases were excluded whose race was 'unknown' or 'other', or whose Hispanic ethnicity was 'unknown'.) b By age group. c By sex.

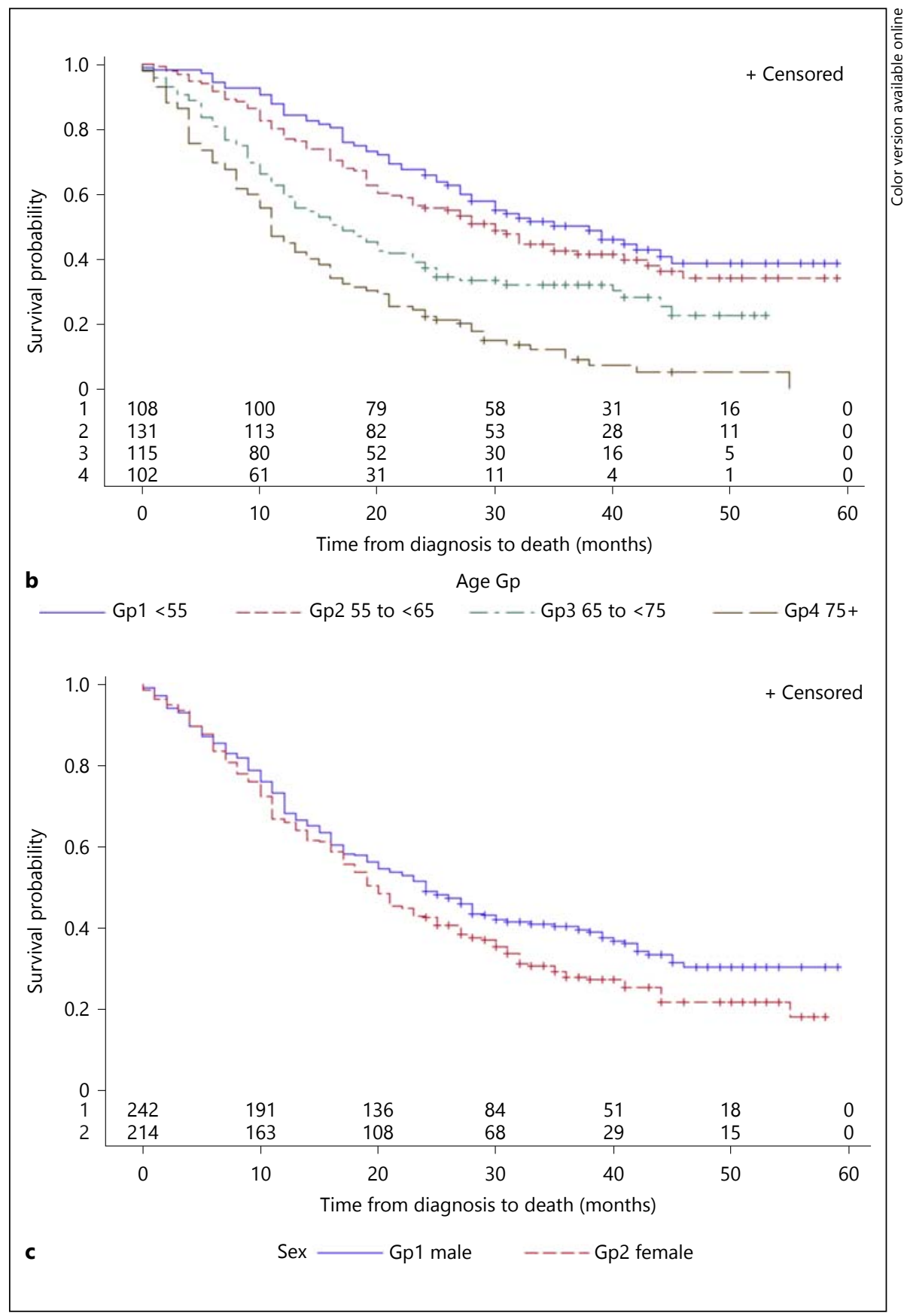

vived that long. This pattern of decreasing survival with age did not vary significantly by sex. In addition, there were no significant differences based on sex, race, or ethnicity group alone (table 2 ).

The multivariate Cox proportional hazards regression model demonstrated a strong age-group effect on survival time (table 3). In comparison to the age group 65 to $<75$ years, the probability of dying was almost half in the youngest group (hazard ratio $(\mathrm{HR})=0.54,95 \%$ CI 0.38 , 0.76 ), while the probability of dying in the oldest group ( $>75$ years) was almost $70 \%$ higher $(\mathrm{HR}=1.68,95 \% \mathrm{CI}$ $1.24,2.27)$. Controlling for age group, the probability of dying did not differ significantly by sex, race, and ethnicity (table 3). Further, there was no statistically significant interaction between sex and age group; that is, HRs by age group were similar between males and females. 
Table 2. Percent of ALS cases surviving beyond diagnosis month, by demographic characteristics, $\mathrm{n}=456^{*}$

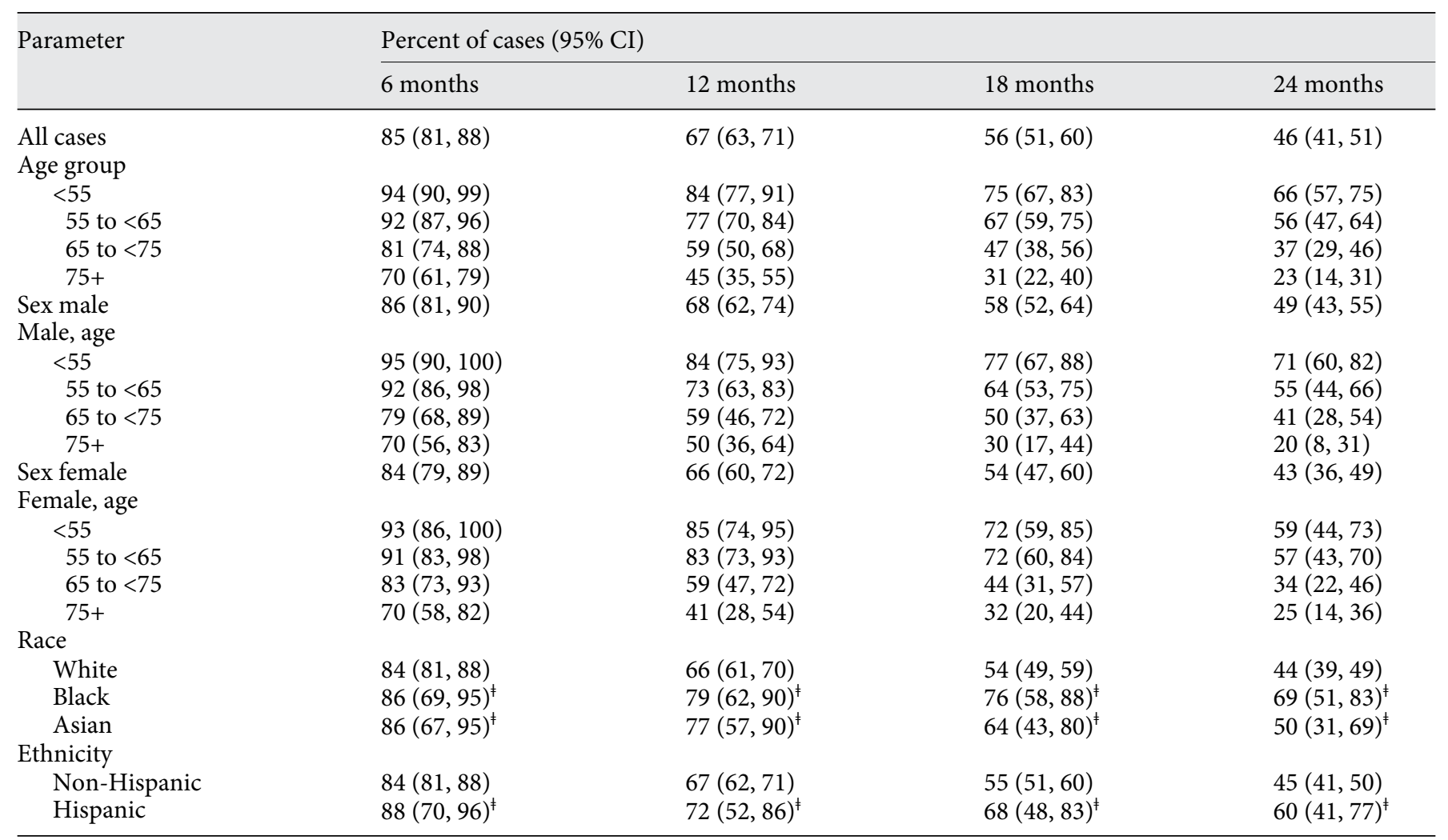

* Of 493 incident cases, 37 were excluded whose race was 'unknown' or 'other', or whose Hispanic ethnicity was 'unknown'.

${ }^{\ddagger}$ Confidence intervals based on Wilson score method, using OpenEpi Confidence Limits for a Simple Proportion (http://www.openepi. $\mathrm{com} / \mathrm{v} 37 /$ Proportion/Proportion.htm). Otherwise confidence intervals based on normal approximation method ( \pm 1.96 (SE)).

Table 3. Adjusted hazard ratios from multivariate Cox proportional hazard model for incident ALS cases, as of December 31, 2013, $\mathrm{n}=456^{*}$

\begin{tabular}{ll}
\hline Parameter & Hazard ratio $(95 \% \mathrm{CI})$ \\
\hline $\begin{array}{l}\text { Age group } \\
<55\end{array}$ & \\
55 to $<65$ & $0.54(0.38,0.76)$ \\
65 to $<75$ & Referent \\
$75+$ & $1.68(1.24,2.27)$ \\
Sex & \\
$\quad$ Male & Referent \\
Female & $1.13(0.90,1.41)$ \\
Race & \\
White & Referent \\
Black & $0.69(0.41,1.17)$ \\
Asian & $0.71(0.40,1.27)$ \\
Ethnicity & \\
Non-Hispanic & Referent \\
Hispanic & $0.81(0.47,1.40)$ \\
\hline
\end{tabular}

* Of 493 incident cases, 37 were excluded whose race was 'unknown' or 'other', or whose Hispanic ethnicity was 'unknown'.

\section{Discussion}

There are limited survival data for persons with ALS in the United States $[7,8,11,13]$, particularly for cases reported by all neurologists in a defined geographic area who used the El Escorial criteria [14] to determine case eligibility. This report contains the first description of the survival of a state-wide cohort of ALS patients in the United States.

The median survival time of 21 months from diagnosis is similar to reports in the literature $[8,9,12,13]$. Older age at diagnosis has been found consistently to be a strong predictor of shorter survival [7-9, 11-13]. In this cohort, the median survival time among those aged less than 55 years at diagnosis was more than three times longer than those aged 75 years or older.

In this study, females had shorter survival than males, though not statistically significant in the multivariate proportional hazards model. Some studies have delineated a difference in survival by sex, perhaps due to differences in site of onset, while others have not $[6,8,9,11]$. 
From the life-table analysis, there were apparent differences in the median survival time based on race and ethnicity. After multivariate adjustment in the proportional hazards analysis, differences by race and ethnicity remained but were not statistically significant; however, these comparisons were based on small case counts among blacks, Asians and Hispanics. Little is known about differences in survival time among different races in the United States. Kazamel et al. found similar median survival times between African Americans (22 months) and Caucasians (19 months) in a clinic-based cohort of ALS cases in Alabama [7]. Based on only ten non-white cases, del Aguila et al. found shorter median survival time among non-whites (14 months) compared with whites (19 months) [8]. We found no other studies that have reported on ALS survival time by Hispanic ethnicity.

Since diagnoses of incident cases were between January 1, 2009 and December 31, 2011, the follow-up time to date has been insufficient to define longer-term survival. Incident cases had a minimum of 24 months and a maximum of 60 months of follow-up time. Nonetheless, follow-up time was sufficient to characterize median survival times as well as percentages of cases surviving up to 24 months in all cases and by demographic groups. The percentage of ALS cases in the N.J., USA cohort who survived past 12 months was $67 \%$ (66\% among whites). This percentage is lower than the percentage reported from a population-based cohort in Lombardy, Italy (76\%) [9], but similar to the percentage reported in western Washington state (66\%) [8].

It is possible that some cases originally reported by neurologists relocated to other states, became residents of those states, and died there. It is also possible that some N.J., USA resident cases could have died in another state and their death certificates have not yet been transferred to N.J., USA. We do not know whether survival time among these possible decedents differs from those for whom we retrieved death certificates.

\section{Conclusion}

This study is the first to examine demographic prognostic indicators, including age, sex, race, and Hispanic ethnicity in a state-wide, population-based cohort of ALS cases. Older age is a strong predictor of shorter survival, and there is some indication of differences based on sex, race, and ethnicity, but these differences were not statistically significantly different when accounting for age. More time is required to fully characterize the shape of the survival curve among longer-term survivors.

\section{Acknowledgments}

The NJ ALS Surveillance team would like to thank all of the reporting providers and their staff members. We would like to thank Dr. Eric Sorenson from the Mayo Clinic and Miro Samawil of the NJ Department of Health for their contribution to the project.

\section{Funding}

This project was funded by McKing Consulting Corporation through a contract funded by the Agency for Toxic Substances and Disease Registry (Contract \#200-2009-32577). Disclaimer: The findings and conclusions in this report are those of the authors and do not necessarily represent the views of the Agency for Toxic Substances and Disease Registry.

Heather Jordan and Jerald Fagliano had full access to all of the data in the study and take responsibility for the integrity of the data and the accuracy of the data analysis.

\section{Authors' Contributions}

Concept and design: Jordan, Fagliano, Kaye; acquisition of data: Jordan, Rechtman, Kaye, Lefkowitz, Fagliano; analysis and interpretation of data: Jordan, Fagliano, Rechtman, Lefkowitz; drafting of manuscript: Jordan, Fagliano, Rechtman, Lefkowitz, Kaye; statistical analysis: Jordan, Fagliano; supervision: Fagliano, Kaye, Lefkowitz.

\section{References}

1 Chio A, Logroscino G, Traynor BJ, Collins J, Simeone JC, Goldstein LA, et al: Global epidemiology of amyotrophic lateral sclerosis: a systematic review of the published literature. Neuroepidemiology 2013;41:118130 .

2 Jordan H, Fagliano J, Rechtman L, Lefkowitz D, Kaye W: Population-based surveillance of amyotrophic lateral sclerosis in New Jersey,
2009-2011. Neuroepidemiology 2014;43:4956.

3 Cronin S, Hardiman O, Traynor BJ: Ethnic variation in the incidence of ALS: a systematic review. Neurology 2007;68:1002-1007.

4 Gundogdu B, Al-Lahham T, Kadlubar F, Spencer H, Rudnicki SA: Racial differences in motor neuron disease. Amyotroph Lateral Scler Frontotemporal Degener 2014;15:114-118.
5 Rechtman L, Jordan H, Wagner L, Horton DK, Kaye W: Racial and ethnic differences among amyotrophic lateral sclerosis cases in the United States. Amyotroph Lateral Scler Frontotemporal Degener 2014; DOI: 10.3109/21678421.2014.971813.

6 Murphy M, Quinn S, Young J, et al: Increasing incidence of ALS in Canterbury, New Zealand: a 22-year study. Neurology 2008;71:1889-1895.
Demographic Effects on ALS Survival Time
Neuroepidemiology 2015;44:114-120 DOI: $10.1159 / 000380855$ 
7 Kazamel M, Cutter G, Claussen G, Alsharabati M, Oh SJ, Lu L, et al: Epidemiological features of amyotrophic lateral sclerosis in a large clinic-based African American population. Amyotroph Lateral Scler Frontotemporal Degener 2013;14:334-337.

8 del Aguila MA, Longstreth WT Jr, McGuire V, Koepsell TD, van Belle G: Prognosis in amyotrophic lateral sclerosis: a populationbased study. Neurology 2003;60:813-819.

9 Pupillo E, Messina P, Logroscino G, Beghi E: Long-term survival in amyotrophic lateral sclerosis: a population-based study. Ann Neurol 2014;75:287-297.

10 Mitsumoto H, Chad DA, Pioro EP: Amyotrophic Lateral Sclerosis. Philadelphia, FA Davis Company, 1998.
11 Czaplinski A, Yen AA, Appel SH: Amyotrophic lateral sclerosis: early predictors of prolonged survival. J Neurol 2006;253:1428-1436.

12 Chio A, Mora G, Leone M, et al: Early symptom progression rate is related to ALS outcome: a prospective population-based study. Neurology 2002;59:99-103.

13 Sorenson EJ, Stalker AP, Kurland LT, Windebank AJ: Amyotrophic lateral sclerosis in Olmsted County, Minnesota, 1925 to 1998. Neurology 2002;59:280-282.

14 Brooks BR, Miller RG, Swash M, Munsat TL; World Federation of Neurology Research Group on Motor Neuron Diseases: El Escorial revisited: revised criteria for the diagnosis of amyotrophic lateral sclerosis. Amyotroph Lateral Scler Other Motor Neuron Disord 2000;1:293-299.
15 New Jersey Department of Health, State Health Assessment Data. http://www4.state. nj.us/dhss-shad/query/DeathQueryTech Notes.html (accessed May 2014).

16 World Health Organization: International Statistical Classification of Diseases and Related Health Problems, Tenth Revision. Geneva, World Health Organization, 1992. 17 SAS $^{\circledR}$ version 9.2. Cary, NC, SAS Institute. 18 Dean AG, Sullivan KM, Soe MM: OpenEpi: Open Source Epidemiologic Statistics for Public Health, Version 2.2.1. http://www. OpenEpi.com (accessed July 2014). 